\title{
A PRÁTICA DOS ROLEZINHOS E O NEODESENVOLVIMENTISMO BRASILEIRO
}

Recebido em: 16/12/2014

Aceito em: 27/08/2015

\author{
Marcela Andresa Semeghini Pereira \\ Universidade de Marília \\ Marília - SP - Brasil
}

RESUMO: Esta pesquisa buscou apresentar as características dos rolezinhos, que são movimentos de ocupação de espaço de consumo, buscando a afirmação e reconhecimento social e explicitação das contradições do país. Os praticantes, normalmente são jovens trabalhadores assalariados, advindos de grandes centros periféricos que, através de ações e políticas praticadas no início década de 2000 até os dias atuais, conquistaram a capacidade de consumir, aumentando as possibilidades de lazer e exigindo a inclusão em espaços que antes não frequentavam. $\mathrm{O}$ acalorado debate gira em torno da legalidade deste movimento, destacando que dentre os direitos garantidos aos sujeitos praticantes está o direito de ir e vir, este é garantido na Constituição Federal de 1988 , de acordo com o disposto no artigo $5^{\circ}$, inciso 15 , e no artigo $8^{\circ}$ da Declaração Universal dos Direitos Humanos e o direito à livre manifestação, expresso no artigo $5^{\circ}$, incisos IV incluindo o direito de opinião que inclui pensamentos, ideias e opiniões bem como a forma em que são expostas. $\mathrm{O}$ direito ao lazer, disposto no artigo $6^{\circ}$ da carta magna é reivindicação deste movimento, sendo este um direito fundamental social. Concluiu-se que o Poder Público, os operadores do direito, a sociedade, as famílias e cada cidadão reflita sobre a aceitação deste novo momento e as possibilidades, de políticas públicas de inclusão para atender as demandas que esse novo cenário social exige. Utilizou-se do método dialético, com consultas em fontes bibliográficas como livros, jurisprudência, revistas e entrevistas.

PALAVRAS-CHAVE: Desenvolvimento Econômico. Direitos Humanos. Atividades de Lazer.

\section{THE LAW OF PRACTITIONERS ROLEZINHOS AND THE ECONOMIC AND SOCIAL DEVELOPMENT OF BRAZIL}

ABSTRACT: This study aims to present the characteristics of rolezinhos which are squatters space consumption, seeking affirmation and social recognition and explanation of the contradictions of the country. Practitioners are usually young employees, arising from large peripheral centers, through actions and policies in the early 2000s to the present day, gained the ability to consume, increasing the possibilities for leisure and requiring the inclusion in spaces that not attended before. The heated debate revolves around the legality of this move, noting that among the rights guaranteed to individuals practicing is the right to come and go, also known as freedom 
of movement or freedom of movement, this is guaranteed in the Federal Constitution of 1988, according with the provisions of Article 5, section 15, and Article 8 of the Universal Declaration of Human rights. The right to leisure, Article 6 of the Federal Constitution claim is this movement, this being a fundamental social right. It was concluded that the Government, jurists, society, families and individual citizens reflect on the acceptance of this new moment and the possibilities for public policy inclusion to meet the demands that this new social scene requires. We used the dialectical method, in consultation with library resources such as books, jurisprudence, magazines and interviews.

KEYWORDS: Economic Development. Human Rights. Leisure Activities.

\section{Introdução}

O rolezinho tornou-se um dos temas mais debatidos e comentados do Brasil, visto que divide opiniões entre as camadas sociais do país e emerge questões polêmicas como a racial e a inclusão social. Após a divulgação midiática deste fenômeno, verifica-se que são movimentos difusos e amplos, com intenção de práticas de lazer e reivindicações sociais e políticas. Eles vêm o shopping como um espaço ideal, onde encontram a reificação do consumo.

Explanou-se sobre as características deste movimento, sendo uma manifestação organizada, sem um líder, reunião de pessoas com vontades comuns, realizadas em áreas abertas ao público, costumeiramente em shopping center. Os jovens praticantes dos rolezinhos ocupam espaços de consumo, normalmente onde se comercializam produtos de marcas famosas.

Referente a este movimento, ocorre reações discriminatórias dos shoppings, operadores do direito e polícia, pela forma como são organizados e pelo momento político que o país atravessa, ainda com recordações das manifestações de rua de 2013. Verifica-se a intenção de apartar os jovens pobres dos espaços públicos e privados dos quais eles não frequentariam normalmente, e o tratamento policial de uma questão social e juvenil. 
Os participantes dos rolezinhos são jovens pobres, moradores de periferias, sem espaços de lazer e de cultura, penalizados por serviços públicos inexistentes ou ineficazes como saúde, escola, infraestrutura sanitária, transporte, lazer e segurança. Assistem programas de televisão e visualizam produtos que os atraem para o consumo, no entanto, não possuem condições financeiras de adquiri-los. Estes jovens sabem utilizar a tecnologia e entrar nas redes sociais para se organizarem e marcarem as reuniões.

Além do debate social e econômico, este movimento incitou a análise jurídica, para que seja refletida a sua legalidade ou ilegalidade e em que situações o poder de polícia deve intervir.

Os rolezinhos trouxeram à baila algumas deficiências por parte do Poder Público, do Estado, do Direito e da própria sociedade. Convida a análise da necessidade de inserção desta "classe" para a manutenção da ordem econômica de um país, também, a importância da efetividade do princípio da dignidade da pessoa humana.

Para o desenvolvimento da presente pesquisa, utilizou-se do método dialético, valendo-se das críticas positivas e negativas apresentadas em artigos, noticiários e debates pessoais. Os dados foram levantados através de pesquisas bibliográficas e entrevistas.

\section{Características do Rolezinho}

Sair de rolê significa dar uma circulada despretensiosa pela vila ou pela cidade. É possível dar um rolê de trem, de ônibus ou a pé. Geralmente, o rolê está ligado ao lazer ou a alguma prática cultural. Sai de rolê o pichador, o skatista, o caminhante, etc. O que vem chamando a atenção de muita gente é como um simples gesto de sair e 
circular de forma livre tem ocupado um papel central nas principais mobilizações juvenis na cidade de São Paulo nos últimos tempos (ALMEIDA, 2014).

Os rolezinhos são manifestações organizadas de uma "classe social" da população que, a partir de uma chamada descentralizada e sem autoridade de comando ou controle, incitam uma reunião de pessoas com interesses em comum em áreas abertas ao público. Possui como característica uma confluência de interesses individuais inicialmente desvinculados que convergem e tomam forma na medida em que se operam numa mesma circunstância de tempo e lugar. Para o sociólogo Giovanni Alves (2014), os rolezinhos são:

[...] ocupação (ou invasão) de espaços do consumo de marca ou territórios do poder simbólico burguês por jovens proletários assalariados pobres que buscam afirmar-se e reconhecer-se socialmente explicitando - deste modo contradições orgânicas da ordem burguesa hipertardia no Brasil. Como os jovens precários de junho de 2013, os "proletaróides" se organizaram utilizando as redes sociais (o acesso a redes sociais demonstra uma credencial de "inclusão social").

Para o autor, os jovens praticantes deste movimento são jovens que trabalham, mas possuem baixo poder de compra, mesmo assim, querem ser inseridos na sociedade e querem ter as mesmas prerrogativas da elite brasileira.

Estes normalmente se organizam em shoppings, pois a condenação da rua como espaço da violência veio acompanhada da sua chegada, também às periferias. Muita gente vai ao shopping tentar encontrar um vazio deixado pelo "fim" das ruas. Para além do consumo, busca-se num shopping um passeio mais livre, solto, e a possibilidade de encontro com pessoas de fora do círculo mais próximo, familiar.

Os rolezinhos em shoppings têm características muito semelhantes com os pancadões de rua realizados de forma espontânea e congregam um número significativo 
de jovens que se reúnem, sobretudo, em torno da expressão cultural do funk, onde expressam a sua ideologia cultural.

As pessoas só encontram uma multidão "sem rosto e coração" (dizeres dos Racionais MC's), e a circulação no interior do shopping não pode ocorrer de forma livre e espontânea. Ela tem regras claras e rígidas dispondo que os pobres podem circular pelo shopping, contanto que finjam pertencer à outra classe social. Mesmo que circulem no shopping sem recursos para consumir, eles devem desejar consumir. Da mesma forma, os negros podem circular pelo shopping espontaneamente, desde que simulem ser brancos nas vestimentas, nos cabelos, no comportamento etc.

O polêmico e depreciado funk é um dos principais mobilizadores dos jovens na metrópole paulistana. E um dos segredos da sua força não está necessariamente no apelo sexual de algumas músicas ou na sua batida envolvente, mas na forma como ressignificou as ruas para esses jovens. Não há necessidade de fingir ser outra coisa, quando exigem os shoppings centers. Ao contrário, é um momento de afirmação dessa identidade periférica.

A teologia do consumo de marcas constitui um fenômeno social juvenil não apenas no Brasil, mas no mundo capitalista global. Na verdade, as crianças e os jovens tornaram-se alvos privilegiados da manipulação do consumo por meio da propaganda e marketing das corporações industriais. A revolução informacional e a constituição da "sociedade em rede" com a disseminação das telas digitais em alta resolução interconectadas 24 horas, elevou à enésima potência o caráter manipulatório do capitalismo industrial. A supervalorização das marcas, como exemplo, a Nike e Adidas, tornou-se o culto dos verdadeiros deuses do Olimpo do capitalismo global: os produtosmercadorias e as marcas das corporações industriais (ALVES, 2014). 
De acordo com o sociólogo Giovanni Alves, o mercado brasileiro de shopping centers cresceu aproximadamente 52\% entre 2006 e 2012. O Brasil, um dos países mais desiguais do mundo, é o país dos shoppings centers. $\mathrm{O}$ espaço social dos shoppings centers é focado, primordialmente, no consumo de mercadorias de marcas, tornando-se o principal espaço da sociabilidade urbana de classe média nas metrópoles, tendo em vista que o espaço público urbano tornou-se, cada vez mais, espaço privado, ocupado pelos grandes condomínios e pelas vias de circulação de veículos (ALVES, 2014).

Os rolezinhos trazem à baila o que nos últimos 15 anos o Brasil viveu, ou seja, um momento de ascensão econômica de todas as camadas da população, que passaram a ter, com o desemprego em baixa e o crédito em alta, acesso aos bens materiais, antes restritos a poucos. Com isso, milhões de brasileiros experimentaram o consumo de bens e serviços e querem cada vez mais. O estímulo para tanto recebem em cada esquina, em cada conversa, virtual ou presencial, e principalmente nos meios de comunicação, que lhes ensinam que o do lócus do consumo é o shopping center, daí os jovens a eles recorrem em seus rolezinhos, onde podem exaltar os símbolos de status social, como as roupas e demais mercadorias e adereços de grife.

Além do desejo de consumo, a mudança no quadro econômico impactou culturalmente o cenário nacional. Mais crianças foram para a escola e jovens de diferentes camadas sociais ao ensino superior, fruto de uma série de políticas públicas que estão colocando nos bancos escolares de todos os níveis setores sociais que anteriormente deles estavam excluídos, isto é, os pobres e os afrodescendentes.

O acesso à educação, mesmo com qualidade social questionável, repercute no desejo dos jovens de terem acesso aos bens culturais, distantes das periferias urbanas e 
hodiernamente aprisionados em shopping centers. Em relação a isso, deve-se dizer que as políticas públicas culturais não avançaram tanto como as que promoveram certa inserção econômica e educacional, deixando a juventude empobrecida sedenta por espaços de lazer e de momentos de fruição cultural. Como cinemas, teatros, casas de shows, restaurantes e espaços de convivência estão nos shopping centers, eles se tornaram, também por isso, ambientes desejados pela juventude empobrecida.

Enquanto as manifestações de junho de 2013 trouxeram à tona o problema crescente da mobilidade urbana, os rolezinhos tornaram público o dilema da falta de espaços urbanos públicos de lazer, onde as pessoas possam confraternizar se divertir praticar esportes, comer algo diferente, com ênfase para a juventude pobre e assalariada da periferia das metrópoles apartadas nos guetos sob a vigilância da Policia Militar.

Os rolezinhos não são manifestações de revoltas, mas sim de ocupação ou invasão de espaços do consumo de marca ou territórios do poder simbólico burguês por jovens proletários assalariados pobres que objetivam afirmar-se e reconhecer-se socialmente divulgando contradições orgânicas da ordem burguesa hipertardia no Brasil. Com o aspecto de se organizaram utilizando as redes sociais, visto que o acesso a redes sociais demonstra uma entrada de "inclusão social”.

Este movimento que a tantos chamaram a atenção, quase sempre de maneira desfavorável, é impactante, pois a reação discriminatória dos shoppings, Justiça e polícia e pela forma como são organizados e pelo momento político que o país atravessa, ainda com lembranças das manifestações de rua de 2013. Há como característica a tentativa de segregar os jovens pobres de regiões ou de espaços públicos ou privados dos quais eles não seriam habituais frequentadores, e o tratamento policial de uma questão social e juvenil. 
Concorda-se que a repressão não soluciona situações como a citada; é um cenário incapaz de garantir direitos, confere apenas uma pacificação instável sob a qual o sentimento de injustiça cresce e sistematicamente volta à baila, na forma de revoltas e violência, formando um círculo vicioso que elimina a possibilidade de uma sociedade que promova a inclusão e a igualdade social.

Os autores Wagner Iglecias e Rafael Alcadipani (2014) informaram em reportagem ao Portal Fórum que, junto com alguns outros shoppings da capital, o Shopping JK Iguatemi, um dos templos do consumo de luxo em São Paulo, conseguiu uma liminar na Justiça impedindo o "rolezaum" que havia sido marcado pelas redes sociais para acontecer no local neste sábado. As portas automáticas que dão acesso ao estabelecimento foram desligadas e passaram a ser blindadas por policiais. Houve, também, a presença de um oficial de justiça na porta do estabelecimento. Caso o organizador do evento aparecesse e fosse reconhecido, seria conduzido a um distrito policial para esclarecimentos, segundo declarou a Veja SP o oficial de justiça. A situação escandalosa foi amplamente divulgada pela imprensa.

Também, em shopping localizado no extremo leste da cidade, a PM chegou a usar bombas e balas de borracha. O Estado tem usado a força para impedir o preconizado direito de jovens pobres e da periferia de ir e vir. Os chamados rolezinhos estão sendo agendados por jovens e adolescentes destes bairros mais distantes por meio das redes sociais, e têm despertado o medo de comerciantes e frequentadores habituais dos shoppings centers. Os primeiros rolezinhos aconteceram em shoppings da periferia, e a presença de seguranças e policiais também ocorreu (IGLECIAS; ALCADIPANI, 2014). 
A expedição de uma liminar, embora compreensível sob o ponto de vista daqueles que temiam a chegada de centenas ou milhares de frequentadores, diferentes do que estão acostumados, torna claro o que todos neste país têm conhecimento e poucas vezes se cita que, apesar dos avanços institucionais e legais que o Brasil conheceu desde a redemocratização, alguns brasileiros são mais cidadãos do que outros.

Reconhece-se que alguns espaços são mais exclusivos do que outros. E o consumo, ainda que incentivado e considerado o fomentador da economia e da sociedade, sendo a meta suprema da felicidade e da realização pessoal, não é, evidentemente, para todos.

Os rolezinhos são, inclusive, caracterizados como uma forma de ação afirmativa. É ocupação político-cultural. Discriminados em sua cultura de resistência, resolveram levar a festa para os lugares onde a própria publicidade os clama, como os shoppings. Os jovens negros e pobres das periferias e favelas das grandes cidades estão, realmente, se organizando. A polêmica gerada, é que estas pessoas se organizam e não querem deixar de serem eles mesmos, de existirem livres em sua riqueza, mesmo quando conquistam a classificação de pertencentes a "Classe C" ou "nova classe média".

O fenômeno rolezinho demonstra o paradoxo da elite brasileira, que por um lado quer crescimento econômico, mas por outro quer manter os pobres à margem da sociedade e da economia. A muralha que o rolezinho revelou é formada por uma justiça muitas vezes conivente com a desigualdade social, constatação esta que deve ser refletida e revista. 


\section{Os praticantes dos Rolezinhos}

Os rolezinhos levaram para dentro do paraíso do consumo a afirmação daquilo que esse mesmo espaço lhes nega: sua identidade periférica. Se quando o jovem vai ao shopping namorar ou consumir com alguns amigos ele deve fingir algo que não é, com os rolezinhos ele afirma a autêntica identidade, mas qual é esta identidade? É o que se propõe tratar neste capítulo.

De acordo com o autor Giovanni Alves (2014), os conceitos de precariado e "proletaróides" são utilizados para caracterizar camadas sociais da classe do proletariado, personagens sociais predominantes e não exclusivas, de manifestações sociais no Brasil do neodesenvolvimentismo.

Intitulam-se as manifestações de junho de 2013 como "a revolta do precariado"; e os rolezinhos ocorridos em dezembro de 2013 e janeiro de 2014 como "a invasão dos proletaróides". Para o autor, a utilização dos conceitos de precariado e "proletaróides" visa caracterizar e dar visibilidade a novos personagens sociais que se constituíram na era do neodesenvolvimentismo (situação sócio/econômica atual do Brasil) ${ }^{1}$ e que explicitam em si e para si contradições da ordem burguesa hipertardia no Brasil (ALVES, 2014).

O mesmo autor esclarece que por um lado, tem-se o precariado caracterizado por jovens altamente escolarizados com inserção salarial precária, imersos na frustração de expectativa de carreira; e por outro lado, há os "proletaróides" que são jovens de

\footnotetext{
1 "Na verdade, neodesenvolvimentismo diz respeito a outro padrão de desenvolvimento capitalista no interior da temporalidade histórica do capitalismo global ou bloco histórico do mercado mundial sob o regime de acumulação flexível predominantemente financeirizado. [...] o neodesenvolvimentismo no Brasil nasce da crise do modo de desenvolvimento neoliberal no Brasil nos primórdios da década de 2000, embora ele próprio - o neodesenvolvimentismo - não consiga romper o bloco histórico do capitalismo neoliberal que deu origem a nova forma de Estado politico do capital (Estado neoliberal), desenvolvida nos últimos trinta anos, tanto no centro quanto na periferia capitalista desenvolvida. Nesse caso, o neodesenvolvimentismo no Brasil é uma variante do desenvolvimento capitalista possível na periferia capitalista inserida na macroestrutura do sistema do capital no plano mundial" (ALVES, 2014).
} 
baixa ou media escolaridade, com emprego formal, mas de alta rotatividade no mercado de trabalho, imersos nos sonhos e anseios de consumo burguês. Os precariado e "proletaroides" não constituem a totalidade social da juventude do proletariado brasileiro, mas representam hoje, duas camadas sociais importantes do proletariado brasileiro, camadas sociais que se tornaram públicas na imediaticidade histórica do neodesenvolvimentismo no Brasil (ALVES, 2014).

Portanto, os sujeitos dos rolezinhos são, em grande parte, os proletaróides, estes muitas vezes faziam parte da classe baixa da sociedade que, através de medidas econômicas e políticas realizadas nos primórdios da década de 2000 até os dias de hoje, obtiveram a capacidade de comprar, ampliando os horizontes de possibilidades de consumo, lazer, exigindo a inclusão em espaços que antes não ocupavam.

Os praticantes dos chamados rolezinhos normalmente são jovens pobres, moradores das grandes periferias, sem opções de lazer e de cultura, punidos por serviços públicos inexistentes ou ineficazes como saúde, escola, infraestrutura sanitária, transporte, lazer e segurança. Assistem televisão e encontram produtos que os seduzem para um consumo que não tem condições financeiras de praticar. Estes jovens sabem utilizar os computadores e entrar nas redes sociais para organizar encontros.

O rolezinho no shopping da à sensação do alardeamento das classes baixas, da base da pirâmide social. Também demonstram o inconformismo com os rumos do país, querem se fazer ouvir e chamar a atenção para as dificuldades e deficiências da nação.

Estes rapazes sentem o quanto nossa sociedade é indiferente e injusta porque exclui, despreza e mantém os descendentes da pobreza na invisibilidade necessária para a manutenção da ordem econômica. No entanto têm conhecimento de que são cidadãos 
amparados constitucionalmente, possuem direitos, e dentre eles está o da inclusão social.

É uma expressão de que habitam um país essencialmente injusto eticamente, e com gritantes desigualdades sociais. Aponta-se que esta sociedade é conservadora e as elites insensíveis e interessadas na manutenção desta ordem, alegando segurança e tranquilidade econômica e social.

Seus integrantes pretendem tornarem-se visíveis e lutam por causas nobres. Por conseguinte, não podem ser tratados com truculência como infelizmente ocorreu em São Paulo por alguns despreparados para lidar com a liberdade, a ponto de um jovem ter sido agredido e ferido injustamente por membros da Policia Militar, o que fez recordar, com pesar, os atemorizantes anos de ditadura militar nos anos 70 em que as democráticas manifestações de ruas eram dissolvidas por cavalo e cassetetes (LIMA FILHO, 2014).

Constata-se que eles denunciam e trazem à tona a desigualdade social cujo verdadeiro nome é injustiça histórica e social. Segundo o IPEA os $10 \%$ mais pobres tiveram entre os anos de 2001 a 2011 um crescimento de renda acumulado de 91,2\% enquanto a parte mais rica cresceu $16,6 \%$. Mas esta diferença não atingiu o cerne do problema, pois o que supera a desigualdade é uma infraestrutura social de saúde, escola, transporte, cultura e lazer que funcione e esteja disponível a toda população (BOFF, 2014).

Os praticantes de rolezinhos não reivindicam apenas o direito de consumir. Eles reivindicam o direito de serem notados e inseridos na sociedade através de práticas de lazer, artísticas e de mostrar suas habilidades culturais: cantar, dançar, criar poemas críticos, celebrar a convivência humana. Eles não são vagabundos e baderneiros, 
anseiam por trabalho para sobreviver e colaborar com a economia da sociedade. O que se nota, no entanto, é que estes direitos lhes são negados, muitas vezes por serem pobres, negros e até mesmo mulheres.

\section{Disposições Normativas do Rolezinho}

É importante recordar que o Estado Democrático de Direito, modelo preconizado na Constituição, tem como fundamento os valores sociais do trabalho, a livre iniciativa, a dignidade da pessoa humana e a cidadania como valores a serem preservados sob-risco de retrocesso do modelo estamental.

Numa democracia não se admiti que haja diferenciação entre àqueles que têm negado o acesso ao consumo por serem considerados "diferentes" e outros livremente. Reporta-se, portanto a tratamento desigual, visto que ir ao shopping não pressupõe a necessidade de consumir bens ou produtos, mas de ser permitida a liberdade de lazer, de se sentir pertencente aquele espaço social, ainda que seja um ambiente elitizado.

Dentre os direitos garantidos aos proletaróides, sujeitos praticantes dos rolezinho, se inclui o direito de ir e vir, também conhecido como liberdade de locomoção ou de livre circulação, este é garantido na Constituição Federal de 1988, de acordo com o disposto no artigo $5^{\circ}$, inciso 15 , e também no artigo $8^{\circ}$ da Declaração Universal dos Direitos Humanos. Quando impõe limitação ao direito de ir e vir, o direito à liberdade também estaria ameaçado. Atualmente, o que se discute é se a proibição de encontros no shopping agendados pelas redes sociais entre pessoas que nem se conhecem, com dia e hora marcados, estaria ou não descumprindo nosso texto constitucional. 
Há definição legal de que os shoppings centers são espaços de livre acesso ao público, no entanto, não são bens públicos, conforme expresso no artigo 98 do Novo Código Civil, que determina: "São públicos os bens do domínio nacional pertencente às pessoas jurídicas de direito público interno; todos os outros são particulares, seja qual for à pessoa a que pertencerem.” Sendo um espaço privado, os proprietários podem reclamar a garantia do direito de propriedade, com o bom senso reivindicado.

O que não se deve aceitar é a proibição do rolezinho mediante identificação e intimação sob o pretexto da garantia ao direito de propriedade, sendo que a justiça tem pendido no sentido de resguardar a propriedade como direito absoluto sem dar atenção a sua função social enquanto aparelho repressivo do estado tem atuado com a intenção de reprimir manifestações sociais que tenha por base a luta pela cidade como espaço plural de pertencimento entre todos, ricos ou pobres, brancos e pretos, moradores dos bairros elitizados e da periferia.

O direito de reunião é direito fundamental, no entanto, não é absoluto. O desígnio de outro direito fundamental, mas certamente aplicável ao caso em estudo, o de ir e vir e, portanto, existem situações em que se faz necessária à ponderação dos interesses em conflito na apreciação do caso concreto.

Para determinar, a razoabilidade, para entendimento em quais os outros direitos fundamentais são afetados por esses rolezinhos em shoppings centers. De uma primeira reflexão, compete-se a citar os seguintes, da Constituição Federal (BRASIL, 2014):

a) "é livre o exercício de qualquer trabalho, ofício ou profissão, atendidas as qualificações profissionais que a lei estabelecer" - inciso XIII do seu artigo $5^{\circ}$;

b) direito de propriedade, atendendo esta à sua função social - incisos XXII e XXIII do seu artigo $5^{\circ}$ 
c) “o Estado promoverá, na forma da lei, a defesa do consumidor" - inciso XXXII do seu artigo $5^{\circ}$

d) "a lei não excluirá da apreciação do Poder Judiciário de lesão ou ameaça a direito" inciso XXXV do seu artigo $5^{\circ}$;

e) "ninguém será privado da liberdade ou de seus bens sem o devido processo legal" inciso LIV do seu artigo $5^{\circ}$;

f) "São direitos sociais a educação, a saúde, a alimentação, o trabalho, a moradia, o lazer, a segurança, a previdência social, a proteção à maternidade e à infância, a assistência aos desamparados, na forma desta Constituição." - $\operatorname{artigo~} 6^{0}$.

Estes são alguns artigos da Magna Carta que explicitam os direitos fundamentais e deveres dos praticantes do movimento estudado.

Propõe-se destacar o direito do consumidor e o consumo em que o aumento do mesmo, decorrente de ascensão social, possibilita maiores investimentos em projetos sociais e na economia, como educação e saúde, alavancando o desenvolvimento e, consequentemente incentivando a garantia de alguns princípios fundantes da ordem econômica, preconizado no artigo 170 da Constituição Federal:

Art. 170. A ordem econômica, fundada na valorização do trabalho humano e na livre iniciativa, tem por fim assegurar a todos existência digna, conforme os ditames da justiça social, observados os seguintes princípios:

I - soberania nacional;

II - propriedade privada;

III - função social da propriedade;

IV - livre concorrência;

$\mathrm{V}$ - defesa do consumidor;

VI - defesa do meio ambiente;

VI - defesa do meio ambiente, inclusive mediante tratamento diferenciado conforme o impacto ambiental dos produtos e serviços e de seus processos de elaboração e prestação;

VII - redução das desigualdades regionais e sociais;

VIII - busca do pleno emprego;

IX - tratamento favorecido para as empresas brasileiras de capital nacional de pequeno porte. 
IX - tratamento favorecido para as empresas de pequeno porte constituídas sob as leis brasileiras e que tenham sua sede e administração no País. (BRASIL, 2014).

Acentua-se a importância do desenvolvimento social e econômico de um país, agregando toda a população e a essencialidade do Direito, que possui a função de garantidor, principalmente dos mais humildes e menos favorecidos economicamente. Portanto, no exemplo dos rolezinhos, as decisões devem ser ponderadas juridicamente, assegurando os princípios preconizados pela Carta Magna.

Também, aos praticantes do movimento, deve-se preservar o direito ao lazer, e oferecer opções para a prática do mesmo, de acordo com o artigo $6^{\circ}$, do texto magno, o lazer é um direito social. O parágrafo $3^{\circ}$, do artigo 217 , da mesma norma, declara que cabe ao Poder Público o seu incentivo. Por sua vez, o artigo 227 expõe que é dever do Estado assegurar o lazer à criança, ao adolescente e ao jovem. Sendo assim, com toda polêmica envolvendo o rolezinho, nota-se que, de modo predominante, o Estado tem abdicado desta responsabilidade, transferindo-a a iniciativa privada.

O direito ao lazer se apresenta como um dos principais elementos protecionistas da dignidade e humanidade considera-se que a tutela do lazer foi estruturada, tanto no plano internacional como no âmbito nacional, como direito fundamental, cuja finalidade era é de estabelecer uma forma legal e segura de certificar a sua proteção.

Em síntese, percebe-se que faltam espaço, estrutura e políticas públicas que garantam o direito dos jovens de praticarem o rolezinho.

\section{O direito a Livre Manifestação dos Praticantes de Rolezinhos}

O direito à liberdade de expressão e, por conseguinte, de livre manifestação, assume um lugar de destaque no processo de democratização com o 
reconhecimento dos direitos fundamentais pela Carta Magna de 1988. Tem, assim, uma missão instrumental referente à afirmação da liberdade individual de pensamento e de opinião que se revele no direito à livre manifestação.

A Constituição de 1988 garante a liberdade de expressão no artigo $5^{\circ}$, incisos IV incluindo o direito de opinião que inclui pensamentos, ideias e opiniões bem como a forma em que são expostas.

Desse modo, a liberdade de expressão no âmbito do ordenamento constitucional brasileiro tem por objeto valorações subjetivas, juízos de valor e crenças pessoais que se distingue do direito à informação, consistente em comunicar fatos. Há, portanto, uma diferença entre um e outro direito, pois enquanto na liberdade de expressão fazemos uso de nossas crenças subjetivas, em que os fatos podem ser verdadeiros ou não, enquanto para o exercício do direito de informação os fatos, pelo menos em princípio, devem ser confiáveis (LIMA FILHO, 2014).

Por constituir em uma das mais fundamentais liberdades democráticas constitucionalmente garantidas, o exercício do direito de manifestação, constituindo uma das dimensões da liberdade de expressão, não pode sofrer restrição além de certos limites que têm fundamento no respeito à ordem pública e a boa-fé. A legislação internacional também prevê este direito, de acordo com a Declaração Universal dos Direitos Humanos, artigo XIX:

Todo homem tem direito à liberdade de opinião e expressão; este direito inclui a liberdade de, sem interferência, ter opiniões e de procurar, receber e transferir informações e ideias por quaisquer meios e independentemente de fronteiras. (ASSEMBLÉIA GERAL DAS NAÇÕES UNIDAS, 2014).

Deve-se enfatizar nesse artigo da Declaração Universal dos Direitos Humanos que o direito à liberdade de expressão refere-se não só a opiniões e pensamentos, como 
muito se acredita, mas também a informações, que podem ou não estar àqueles relacionadas. Há, portanto, segundo Arael Menezes da Costa (1979, p. 20), "liberdade de expressão do pensamento e da informação". Isso amplia a esfera dessa liberdade, pois falar sobre informação implica falar também sobre todo o seu processo de vida, que é não só a divulgação, mas também a busca e o acesso à mesma.

Uma das liberdades públicas previstas no artigo $5^{\circ}$ da Constituição é promover o debate sobre temas que dizem respeito à cidadania, e os jovens enquanto cidadãos, não são privados dessa liberdade pelo fato de escolher locais que, embora abriguem empreendimentos privados, não deixam de se constituir em espaços públicos. Por conseguinte, não podem ser penalizados pela circunstância de denunciar alguma irregularidade ou por fazer crítica a algum aspecto empresarial ou aos poderes constituídos.

Concorda-se, portanto, que a liberdade de expressão e de manifestação deve ser exercida de forma pacífica e com demarcações, o que não se pode, como tem ocorrido, é vetar o exercício desse direito com o argumento de um potencial dano ao patrimônio privado, pois isso se mostra desproporcional, na medida em que impede o exercício do próprio direito que o a Magna Carta assegura.

Só se é livre quando existe o Direito, regulamentando o convívio social; e isso só é possível respeitando e fazendo respeitar a individualidade e a intimidade de cada um de seus membros e o bem coletivo, através do estabelecimento de limites expressos legalmente, que, de certa forma, aderem-se naturalmente a cada direito. Há, portanto, fronteiras para o exercício da liberdade de expressão, pois esta não é absoluta e sim uma manifestação do próprio caráter societário dos indivíduos, que baseiam todas as suas relações de convivência na reciprocidade do respeito à pessoa e aos seus pertences, 
assim como à ordem instituída. De encontro com esta informação, a Declaração Americana dos Direitos e Deveres do Homem dispõe:

\begin{abstract}
O exercício dessas liberdades pressupõe diversas responsabilidades e, por consequência, pode estar sujeito a certas formalidades, fixadas por lei e que sejam necessárias à segurança nacional, da integridade territorial, da segurança pública, da defesa da ordem e prevenção contra o crime ou para proteger a saúde ou a moral, a reputação ou os direitos dos outros, impedir a divulgação de informações confidenciais ou para garantir a autoridade e a imparcialidade do poder Judicial. (COMISSÃO INTERAMERICANA DE DIREITOS HUMANOS, 2014).
\end{abstract}

Como adverte Gomes Canotilho (2003, P. 467), as restrições de direitos fundamentais somente se mostram justificadas com base numa relação especial de poder, mas sem fundamento expresso na Constituição, na medida do estritamente necessário para salvaguardar bens constitucionalmente positivados e expressamente defendidos pelas instituições onde se desenvolvem estas relações.

Contudo, admite-se que nenhuma liberdade deve ser exercida para apoiar "o direito ao insulto", devendo se entender que isso ocorre quando a expressão inclui manifestações vexatórias para a emissão da mensagem ou quando se aprecia ânimo de injúrias ou humilhações em seu emissor, quando revele xenofobia ou incentive a atos de violência ou de discriminações, apologia ao crime, ao terrorismo e outros atos que atentem contra o valor da dignidade da pessoa humana (LIMA FILHO, 2014).

Pode-se asseverar, que referido direito não pode ser exercido como anteparo para violar a dignidade da pessoa, na medida em que este valor, além de fundar todo o ordenamento jurídico, também encontra tutela nos diversos Tratados e Convenções Internacionais sobre Direitos Humanos, cujo respeito à própria Constituição Federal impõe nos artigos. $1^{\circ}, 4^{\circ}$ e $5^{\circ}$.

O jurista e ministro do Supremo Tribunal Federal Luís Roberto Barroso (2013, P. 371-372), destaca, o fértil desenvolvimento teórico do constitucionalismo atual no 
sentido da aplicação dos direitos fundamentais às relações privadas. Este anota situações em que o exercício do direito de propriedade ou da autonomia de vontade confronta com valores, princípios e normas expressos e implícitos no texto da Constituição: a) escola que não admite filhos de pais divorciados; b) demissão de empregada em caso de gravidez; c) demissão de jornalista por ter emitido opinião diversa à do dono do jornal e d) clube de futebol que impede o ingresso de jornalista em seu estádio por conta de críticas veiculas pelo profissional.

Diante dessas declarações, apoia-se que somente as restrições ou limitações de acesso ao shopping center coerentes e consonantes com a ordem jurídica são aceitas juridicamente como válidas. É factível identificar alguns casos como o não pagamento de ingresso ou entrada forçada quando essa for devidamente instituída; não identificação pessoal quando essa for devidamente requisitada; utilização de trajes inequivocamente inadequados; porte de armas ou objetos inadequados; quando há limitação de pessoas, por segurança e qualidade do espaço e comportamento agressivo para com pessoas e coisas.

Neste diapasão, também se permite identificar hipóteses em que a restrição ou limitação não é admitida como juridicamente válida: a) pela raça ou cor da pele; b) pela idade; c) pela condição física; d) pelas preferências em termos de vestimentas; e) pelo local de moradia; f) pelas preferências sexuais e g) pela forma de chegada ao estabelecimento.

\section{Premência de Ações Suscitadas pelos Rolezinhos}

Evidentemente, o entendimento de que não é possível impedir a entrada de pessoas em um shopping center invocando as motivações já expostas não significa a 
admissão de comportamentos irregulares ou criminosos, tais como: afronta à tranquilidade; bagunças e tumultos; agressões físicas; destruição de patrimônio, furtos e outros. As condutas ilícitas podem e devem ser reprimidas, pela segurança dos estabelecimentos e pelas forças policiais. Nesse sentido, utiliza-se como exemplo decisão judicial proferida em Manaus em relação aos rolezinhos, pela juíza de Direito Simone Laurente de Figueiredo ${ }^{2}$.

No dia 25 de julho de 2014, a $11^{\text {a }}$ Câmara Cível do Tribunal de Justiça de Minas Gerais determinou que o Facebook excluísse de seus conteúdos as mensagens contendo chamadas para encontros no Shopping Contagem, denominados de rolezinhos, sob pena de multa diária de $\mathrm{R} \$ 1$ mil, limitada em $\mathrm{R} \$ 50$ mil. A decisão confirma liminar expedida pelo juiz da $4^{\text {a }}$ Vara Cível de Contagem:

EMENTA: AGRAVO DE INSTRUMENTO -- TUTELA ANTECIPADA FACEBOOK - CONVOCAÇÃO - ROLEZINHO - CONTEÚDO ILEGAL DEVER DE EXCLUSÃO DAS PÁGINAS DA INTERNET - RISCO DE DANO IRREPARÁVEL - MEDIDA CONCEDIDA - MANUTENÇÃO. RECURSO NÃO PROVIDO. 1) A tutela antecipada está prevista no art. 273 do CPC e exige três pressupostos genéricos e cumulativos: (I) prova inequívoca; (II) verossimilhança das alegações e (III) reversibilidade dos efeitos do provimento jurisdicional. A tutela antecipada também exige a presença de um de seus pressupostos alternativos: (I) perigo ou (II) abuso do direito de defesa/manifesto propósito protelatório. 2) Havendo prova inequívoca das alegações da parte a conduzir à verossimilhança das alegações, impõe-se a concessão da medida, mormente quando presente o risco de dano irreparável ou de difícil reparação. (TRIBUNAL DE JUSTIÇA DE MINAS GERAIS, 2014).

Esta decisão evidencia a preocupação e insegurança dos proprietários destes espaços, do Poder Público e dos operadores do Direito com as reuniões realizadas pelos proletaróides. Constata-se que não sabem como manejar esta situação, é um momento

\footnotetext{
2 A juíza de Direito Simone Laurent de Figueiredo, da Central de Plantão Cível de Manaus/AM, determinou na última sexta-feira, 24, que os participantes do 'Movimento Rolezinho Manaus' evitassem tumultos, correrias, algazarras, atos de vandalismo e uso de equipamentos de som em alto volume durante "rolezinho" no Manauara Shopping, na capital manauense". Disponível: http://www.migalhas.com.br/Quentes/17,MI194309,51045-

Rolezinho+em+shopping+de+Manaus+e+permitido+com+restricoes. Acesso em: 28 jul. 2014.
} 
de adaptação e reflexão sobre as melhores opções e alternativas para incorporar estes grupos a um meio, aparentemente, hostil.

O direito não atingiu um patamar suficiente para resguardar o princípio da dignidade humana em sentido amplo quando a nova concepção de cidadania em seu sentido autêntico é de participação popular para além de classes sociais, sotaques, origem, raça ou condição social. O povo não pode mais ser desprezado em nome da propriedade individual, a sociedade anseia por justiça distributiva e social e as instituições não dão ênfase aos dilemas humanos do novo milênio tendo a dignidade da pessoa humana preterida pelo lucro, ambição e busca de poder.

Os jovens da periferia se estavam interessados apenas em dar um rolê, agora estão se dando conta de sua força. E não têm se contentado em ser parte daquele Brasil obsoleto, que se esconde longe dos olhos da população em sua obscura zona de conforto. Os rolezinhos são resultados da falta de espaços públicos de lazer e divulgação de trabalhos artísticos como músicas, poesias, pinturas, contos e esportes. O direito precisa se atualizar, caminhando pari passu com as mudanças sociais.

Esses jovens querem ser vistos como protagonistas, sujeitos que fazem se destacam, tendo a oportunidade de dar algo à sociedade. Eles não querem ser reconhecidos por meio da exotização e da romantização da cultura popular, mas por uma apropriação singular dos símbolos mais altos do poder e dos espaços. O rolezinho é um alívio temporário capaz de transmutar exclusão em inclusão - inclusão ainda longe de ser de fato e de direito.

Finalizando a pesquisa, cabe destacar que está surgimento uma nova situação econômico-social no Brasil, onde a juventude da periferia está melhorando suas condições de vida, por meio dos programas sociais, como a Universidade para Todos - 
ProUni, Ensino Técnico - Sisutec, Financiamento Estudantil - FIES (para cursos de graduação, mestrado e doutorado) entre outros, e no mercado de trabalho em expansão. Esta melhora na qualidade de vida é resultado do desenvolvimento econômico do país, no entanto o que se nota é que a sociedade não está preparada para receber e até mesmo aceitar os proletaróides.

É imperioso que o Poder Público, os operadores do direito, a sociedade, as famílias e cada cidadão reflita sobre a aceitação deste novo momento e as possibilidades de políticas públicas de inclusão para atender as demandas que esse novo cenário social exige.

\section{Conclusões}

Os rolezinhos emergem os últimos anos de desenvolvimento econômico e social do Brasil, caracterizado pelas baixas taxas de desemprego e o crédito em alta, acesso aos bens materiais, limitados a alguns. Com o chamado "neodesenvolvimentismo" os brasileiros provaram o consumo de bens e serviços e ambicionam mais. Neste contexto, os jovens recorrem aos rolezinhos, onde podem exibir os símbolos de status social, como as roupas, as músicas e outras mercadorias e enfeites de grife. Observa-se que juventude da periferia está melhorando suas condições de vida, muitas vezes com o auxílio dos programas sociais.

A necessidade do consumo, preferencialmente de produtos de marcas, é uma realidade social local e mundial. Nota-se que as crianças e os adolescentes tornaram-se públicos preferenciais da alienação provocada pelo consumo através de propaganda e marketing das corporações industriais. A facilidade de acesso às informações e a 
chegada da "sociedade em rede" com a propagação das telas digitais em alta resolução interconectadas 24 horas, elevou o caráter manipulatório do capitalismo.

Dentre os direitos conferidos aos proletaróides, praticante dos rolezinhos está uma das mais fundamentais liberdades democráticas constitucionalmente garantidas, o exercício do direito de manifestação, constituindo uma das dimensões da liberdade de expressão, sofrendo restrições limitadas, que têm fundamento no respeito à ordem pública e a boa-fé. O direito de consumir, que propulsiona o desenvolvimento e incentiva a garantia de alguns princípios fundantes da ordem econômica.

É evidente que o cenário socioeconômico que o país presencia é um momento inusitado e demandante de propostas e alternativas para a resolução dos conflitos e, principalmente o acolhimento social de todas as classes econômicas, sociais, raciais, de gênero etc.

Enfim, o que se abriga na presente pesquisa, é a preeminência da defesa do princípio da dignidade da pessoa humana, com ênfase aos trabalhadores, que necessitam de sua força para vencer as misérias materiais e ideológicas e controlar, através da luta, a condição diuturnamente vilipendiada de sujeito da história. Em sintonia, é importante que as organizações absorvam que as ações reivindicatórias precisam ter autonomia em relação às instituições mediadoras da ordem incluindo, neste rol, o Direito.

\section{REFERÊNCIAS}

ALMEIDA, R. S. de. O rolezinho da juventude nas ruas do consomo e do protesto. Juventude em Movimento. Disponível em: http://www.diplomatique.org.br/artigo.php?id=1581 . Acesso em: 31 jul. 2014.

ALVES, G. Precariado e "proletaróides" - Uma nota metodológical Disponível em: http://blogdaboitempo.com.br/category/colunas/giovanni-alves/. Acesso em: 27 jul. 2014. 
ASSEMBLÉIA GERAL DAS NAÇÕES UNIDAS. Declaração Universal dos Direitos Humanos. $1948 . \quad$ Disponível em: http://portal.mj.gov.br/sedh/ct/legis_intern/ddh_bib_inter_universal.htm. Acesso em: 01 ago. 2014.

BARROSO, L. R. Curso de Direito Constitucional Contemporâneo. 4a Edição. São Paulo: Editora Saraiva, 2013.

BOFF, L. Os rolezinhos nos acusam: somos uma sociedade injusta. 28 de Janeiro de 2014. Disponível em: http://www.brasil247.com/pt/247/artigos/128399/Os-rolezinhosnos-acusam-somos-uma-sociedade-injusta-e-segregacionista.htm. Acesso em: 31 jul. 2014.

BRASIL. Constituição da República Federativa do Brasil de 1988. Brasília, 5 de outubro de $1988 . \quad$ Disponível em: http://www.planalto.gov.br/ccivil_03/constituicao/constituicao.htm. Acesso em: 12 ago. 2014.

Código Civil. Lei $\mathrm{n}^{\mathrm{o}} 10.406$, de 10 de janeiro de 2002. Disponível em: http://www.planalto.gov.br/ccivil_03/leis/2002/110406.htm. Acesso em: 01 ago. 2014.

COMISSÃO INTERAMERICANA DE DIREITOS HUMANOS. Declaração Americana dos Direitos e Deveres do Homem. Bogotá, 1948. Disponível em: http://www.cidh.oas.org/basicos/portugues/b.Declaracao_Americana.htm. Acesso em: 01 ago. 2014.

COSTA, A. M. da. Liberdade de Expressão e Controle da Informação. João Pessoa: Universitária, 1979.

GOMES CAnOtilho, J. J. Direito Constitucional e Teoria da Constituição. Coimbra: Almedina, 2003.

IGLECIAS, W.; ALCADIPANI, R. Os rolezinhos e um Apartheid a brasileira. Portal Fórum. Disponível em: http://www.revistaforum.com.br/blog/2014/01/os-rolezinhosum-apartheid-a-brasileira/. Acesso em: 31 jul. 2014.

LIMA FILHO, F. das C. O "rolezinho" e o direito de livre manifestação. 09 fev. 2014. Disponível em: http://www.direitonet.com.br/artigos/exibir/8348/O-rolezinho-eo-direito-de-livre-manifestacao. Acesso em: 31 jul. 2014.

TRIBUNAL DE JUSTIÇA DE MINAS GERAIS (TJMG). TJ determina a rede social que retire convocações para rolezinho. Decisão de 25 jul. 2014. Disponível em: http://www.tjmg.jus.br/portal/imprensa/noticias/tj-determina-a-rede-social-que-retireconvocacoes-para-rolezinho.htm. Acesso em 06 ago. 2014. 


\section{Endereço da Autora:}

Marcela Andresa Semeghini Pereira

Rua Antônio Alpino, 270, Jardim América

Marília - SP - 17.505-240

Endereço Eletrônico: ma.andresa@gmail.com 